general economic theorists is by no means incongruous. M. Massé is in the Keynesian tradition.

The first volume deals with stock-piling for a known future, and is governed by a principle of the Maximization of Profit. The second volume discusses stock-piling against the needs of an uncertain future, and is governed by a principle of the Maximization of the Expectation of Profit. In the first case a stable solution exists in general if marginal profit is subject to decreasing returns; but there are some important special cases arising from the fact that both flow into stocks, and the level of stocks, are bounded. Stocks, for example, cannot be negative. M. Massé discusses various special types of profit-function, and then allows for the complication that birds in the hand are worth two in the bush; that the passage of time applies positive or negative rates of interest or discount to stocks and to satisfactions. Wheat deteriorates; money, set at interest, grows.

The economist's interest will quicken as he turns to the second section-to the world of probabilities, which is so much more like the real world. The profit, the mathematical expectation of which is to be maximized, must be measured in terms of satisfaction or utility rather than in terms of money, and can indeed provide a definition and a measuring-rod for the utility of money. But since a small change in a 50 per cent chance of success is psychologically quite different from a small change in a 1 per cent chance of success, the principle of the Maximization of the Expectation of Profit requires to be tempered by a principle of the Limitation of Risk ; and this introduces new difficulties and indeterminacies.

M. Massé now adapts the methods of marginal analysis to an uncertain world, and discusses various types of marginal expectation of profit. The net flow into reserves may, in a given period of time, be arbitrarily given as a set of probabilities of different values; or given as a probability function of previous history (that is, of the flows in all previous periods) ; and the profit may also be known only in probability -as when a farmer is ignorant both of the amount and the price of his next crop. Cases of these kinds are discussed.

Enough has been said to indicate the wide interest and generality of the methods used. But it must be repeated that M. Massé is a true man of science; step by step he has tested his theories against his observation of the everyday world. Nor does he confuse the reader by an unnecessary use of mathematical symbols. $\mathrm{He}$ is therefore worthy of an honourable place among mathematical economists, who are too frequently obscure and too frequently fail to match their abstractions against reality.

Charles F. Carter

\section{TERPENE CHEMISTRY}

\section{The Terpenes}

By Dr. J. L. Simonsen. Vol. I : The Simpler Acyclic and Monocyclic Terpenes and their Derivatives. Second edition, revised by Dr. J. L. Simonsen and Dr. L. N. Owen. Pp. xvi +479 . (Cambridge: At the University Press, 1947.) 30s. net.

$7 \mathrm{HE}$ enormous variety of constituents to be found in the essential oils of plants constitutes one of the most impressive phenomena of organic chemistry. These fragrant oils consist usually of complex mixtures of acyclic, alicyclic, and aromatic substances. The carbon skeletons of the acyclic and alicyclic sub. stances may be pictured as built up by the fusion of isoprene nuclei of five carbon atoms, arranged with exceedingly few exceptions in an orderly head-to-tail manner. This simple conception leads at once to molecular frameworks of terpenes composed of two or more of these nuclei, and forming acyclic, monocyclic, or polycyclic structures.

Although they are produced so lavishly in the plant world, no satisfactory conclusion has yet been formed concerning the origin and function of terpenes and their oxygenated derivatives. To tho organic chemist they offer a harmonious symphony of subtle variations on an underlying molecular theme. Their delicate molecular fabrics, usually of an asymmetric cast, are of equal interest to the stereochemist. To the botanist they often provide a means of differentiating between specific or varietal forms of plants showing little morphological divergence.

British investigators, working in various parts of the world, have made noteworthy contributions to this field of organic chemistry, and it is appropriate that the outstanding modern account of the subject should stand to the credit of one of the most eminent of these investigators. Dr. Simonsen's comprehensive treatise, first issued in 1931, is valued alike by specialists in terpene chemistry and organic chemists in general.

The volume now under notice is concerned mainly with $\mathrm{C}_{10}$-skeletons embracing the unsaturated hydrocarbons known as acyclic and monocyclic terpenes, respectively, and the derived alcohols, aldehydes, ketones, and oxides. In the revision the author has had the help of Dr. L. N. Owen in covering the literature until the end of 1945 ; in some instances even later work has been noticed. During the War, the activities of most workers in this field were interrupted, and groups of experienced workers were dispersed beyond all hope of reassemblage. Recovery will necessarily be slow in reconstituting such schools, owing to the delicate character of terpene research, in which technique and experience count for so much. Nevertheless, a great deal of new information had been gathered between 1931 and the outbreak of war. This first revised volume welcomes such interesting newcomers as angustione, dehydroangustione, leptospermone, and cryptone, from the Australian flora, and piperitenone and isopiperitenone from North Africa; it records much fresh information about the phellandrenes, menthols, carvomenthols, piperitones, piperitols, etc.; and it brings forward Ruzicka's new seven-carbon-atom ring for irone.

The plan and scope of the work remain unaltered. The first volume has been increased by about sixty pages, and a revised and enlarged edition of the original second volume is in preparation. The book is beautifully printed, with neat and clear structural formulæ, and each page carries its own documentation. For a long time essential scientific text-books and works of reference of British origin have been so difficult to obtain-in marked contrast to the efflorescence of ephemeral 'literature' in which the bookshops abound-that it is peculiarly gratifying to find a standard work of high calibre emerging from a British press during this period of eclipse. In the interests of British science and of general British prestige, it is equally imperative that established works of this kind should again become freely available and that the virtual ban existing on the publication of new British books on science should be speedily removed.
JoHN READ 